\title{
Cosmic rays as a novel hypothetic explanation for the ancient mentioned effects of sleeping under the night sky
}

Farshad Amini-Behbahani ${ }^{1,2}$, Jafar Ghafarzadeh ${ }^{1,2}$

${ }^{1}$ Research Institute for Islamic and Complementary Medicine, Iran University of Medical Sciences, Tehran, Iran

${ }^{2}$ School of Persian Medicine, Iran University of Medical Sciences, Tehran, Iran

\section{Type of article: Letter to Editor}

\begin{abstract}
Traditional medicine scientists believed that sleeping under the stars and moonlight is not healthy because it brings about nose bleeds and respiratory problems. In Avicenna's view, the spirit and its tendency to the light are introduced as main etiology, which cannot explain star light as a proper etiology. In modern knowledge, it seems cosmic rays that reach our planet's atmosphere by electron cascade, play a key role. Internal organs' electrical charge distribution disturbance caused by these electrons can lead to irregular spasms in the muscular walls of arteries and other organs. These interactions may finally lead to circulation (epistaxis and hypertension) and respiratory (catarrh) problems.
\end{abstract}

Keywords: Avicenna; Epistaxis; Hypertension; Catarrh; Sleep; Cosmic rays

\section{Dear editor,}

Although sleeping under the stars and moonlight seems romantic and beautiful, since prehistoric times, Homo sapiens have spent their time finding and making shelters to survive at night. Today, by counting on secure systems, guns, lace tents and recreation vehicles (RVs) which protect us from animals, insects and noise, we can be confident enough to enjoy camping without tents. A thousand years has passed since Avicenna (980-1037CE) wrote in his Canon: "Sleeping under sun and moonlight shining above the head can cause bloody sputum (because of humors' movement) and snoring (because of trachea and throat collapse)" (1). Eight hundred years later, one of his followers Hakim Gilani (1788-1907CE) mentioned those side effects in his book, using similar words: nose bleeding and catarrh (2). An ancient suggested physiology for this phenomenon is the tendency of the spirit toward the light, which leads to stimulation of the blood. The mentioned spirit is a medical-spirit (very similar to bio-electromagnetic pulses) which is different from the celestial spirit. The main direction of the spirit in wakefulness is from inside to outside, but its direction changes through sleeping, from outside to inside the body (1). Light can have an effect on the direction of this movement; in wakefulness, the spirit's movement toward the light brings about a feeling of happiness (which in Avicenna's view is described by sudden movement of the spirit toward the outside for perception of a pleasant object). In sleeping, movement of the spirit toward external lights is opposite to the natural direction and causes sleep disorder. Also, the spirit's anxious movement acts as a trigger for the production of vapors and wind in the body which can lead to catarrh and fasciculation. Extra production of mucus and muscular spasm can be easily tolerated in wakefulness, but in sleeping, they are harmful and can cause upper respiratory obstruction. Because celestial bodies are the most luminous objects in this view, the spirit's excitement will increase. Although the logic of the theory for sleeping under the sunlight was acceptable in ancient times, it seems inappropriate for sleeping under the stars especially on moonless nights, according illuminance which is less than one candle at one meter distance (3). So, the question is, which light at night could cause spirit disturbance?

\section{Corresponding author:}

Jafar Ghafarzadeh, MD-PhD candidate, School of Traditional Medicine, Iran University of Medical Sciences, South Hafez Street, Behesht Street, Tehran, Iran. Tel: +98- 21-55580388, E-mail: ghafarzadehjafar@gmail.com

Received: September 13, 3017, Accepted: January 31, 2018, Published: February 2018

iThenticate screening: February 04, 2018, English editing: February 05, 2018, Quality control: February 12, 2018

This article has been reviewed / commented by four experts

(C) 2018 The Authors. This is an open access article under the terms of the Creative Commons Attribution-NonCommercialNoDerivs License, which permits use and distribution in any medium, provided the original work is properly cited, the use is non-commercial and no modifications or adaptations are made. 
Seventy years have passed Professor Powell in his noble lecture, described a cosmic ray as "a thin rain of charged particles" (4). An electron shower is the product of the interaction of a cosmic ray and our planet's atmosphere. Muons (high speed negative heavy particles) and electrons (both negative and positive) are the most common particles of a cosmic ray at sea level (5). They are responsible for air ionization at sea level and penetrate deeply under the ground (4). Muons pass through our bodies and we do not have any shield against them. Thus, we are used to them, but a proper roof (even a leathern tent) can act as a diagonal barrier against electrons, and diminish the energy of some others. One suggested mechanism for describing the side effect of sleeping in unroofed places is the disturbance of the body's electrical charges distribution by an electron shower. Man-made static electric fields elevate body surface electrical charges (6), but the produced cascade's electrons by cosmic ray have greater penetration than ordinary lab-made electron emissions (because of their higher energy level). Evaluations show that the intensity of cosmic ray induced electrons and positrons at the earth's surface differ between 30 , 6, and 0.2 $\mathrm{m}-2 \mathrm{~s}-1$ above 10,100 and 1000 mega electron volts, depending on the altitude and latitude (7). Although the accumulation of beams seems low, through long-time exposure they will show effects. These electrons can pass through the skin and reach internal organs. The human body confronts excessive charges and internal charge distribution disturbance. There are some adaptation mechanisms in wakefulness for discharging the extra accumulation of electricity such as peripheral blood circulation and touching an uncharged environment. But when we are sleeping, we lose movement and the chance of connection with uncharged objects. Also, peripheral blood circulation (as a low electrical resistant) is diminished during the main part of sleeping (8). Excessive internal charges may interact with muscle fibers' action in the walls of arteries, stomach and trachea. The consequence could flourish by periodic hypertension. Epistaxis is recognized as a symptom of hypertension (9). Electrical charge irregularity can cause spasms in the trachea and throat. In the stomach, it can produce irregular spasms and reflux (which can itself decrease bronchial diameter and mucus transport, and increase secretion of mucus) (10). Also, electrical stimulation can directly cause mucus hyper secretion (11). So, bloody sputum (1) could be logically explained by epistaxis due to periodic hypertension; and snoring (1) could be described by tracheal collapse due to spasm and increased secretion of mucus. The accuracy of the hypothesis should be evaluated by blood pressure measuring during sleep under the sky, maybe by a modified polysomnography. Inversely, to prevent extra relaxation of internal organs which can have an effect on blood pressure measuring, barometers should not create a way for grounding of the body $(12,13)$. Also, because of higher "cosmic ray related electron flux" at higher altitudes and latitudes $(7,14)$, measuring at these places can provide better results. The evaluation is better done at nighttime, because daytime sleeping (even under a roof) is a known etiology of catarrh (15) which could be explained by a combination of different mechanisms.

Authors did not have access to proper instruments for evaluating the hypothesis, but possible detection of periodic hypertension or snoring caused by sleeping under the sky, by using portable polysomnography in future, should not be of concern to people or companies who are interested in or have invested their money in "camping under the stars". Maybe grounding of the bed is a proper solution for these problems.

\section{Acknowledgments:}

This article was written at Iran University of Medical Sciences and Tehran University of Medical Sciences. Special thanks to Dr. Mansoor Keshavarz for encouraging writers to share their ideas.

\section{Conflict of Interest:}

There is no conflict of interest to be declared.

\section{Authors' contributions:}

Farshad Amini-Behbahani: gathering sources, idea, and writing draft; Jafar Ghafarzadeh: corresponding, assistance, reviewing final draft.

\section{References:}

1) Avicenna. Canon of Medicine (Book three Technique No. one). Beirut -Lebanon: Alaalami Library publication; 2005: Vol. 2; 281-2.

2) Gilani MK. Hefz ol Sehha e-Naseri. Tehran: Almaee publication; 2009: 139-40.

3) Schlyter P. Radiometry and photometry in astronomy. Stockholm, Sweden. 1997-2009; Available From: http://stjarnhimlen.se/comp/radfaq.html 
4) Powell CF. The cosmic radiation. Nobel Lecture, Physics 1942-1962. Elsevier Publishing Company; 1964: 144 -157. Available from: http://www.nobelprize.org/nobel_prizes/physics/laureates/1950/powelllecture.pdf.

5) Jelley JV, Porter NA. Čerenkov Radiation from the Night Sky, and its Application to $\gamma$-Ray Astronomy. Quarterly Journal of the Royal Astronomical Society. 1963; 4: 275-93.

6) Kwan-Hoong NG. Non-Ionizing Radiations - Sources, Biological Effects, Emissionsand Exposures. Proceedings of the International Conference on Non-Ionizing Radiation at UNITEN (ICNIR2003) Electromagnetic Fields and Our Health 20th - 22nd.

7) Gaisser TK, Stanev T. Cosmic ray. Physics Letters B667, 1. 2008. Available From: http://pdg.lbl.gov/2009/reviews/rpp2009-rev-cosmic-rays.pdf.

8) Khatri IM, Freis ED, Hemodynamic changes during sleep. J Appl Physiol. 1967; 22(5): 867-73. doi: 10.1152/jappl.1967.22.5.867. PMID: 6026506.

9) Charles R, Corrigan E. Epistaxis and hypertension. Postgrad Med J. 1997; 53: 260-1. doi: 10.1136/pgmj.53.619.260.

10) Lang IM, Haworth ST, Medda BK, Roerig D, Forster HV, Shaker R. Airway responses to esophageal acidification. Am J Physiol Regul Integr Comp Physiol. 2008; 294(1): R211-9. doi: 10.1152/ajpregu.00394.2007. PMID: 17928508.

11) Ramnarine SI, Hirayama Y, Barnes PJ, Rogers DF. Sensory-efferent' neural control of mucus secretion: characterization using tachykinin receptor antagonists in ferret trachea in vitro. Br J Pharmacol. 1994; 113(4): 1183-90. doi: 10.1111/j.1476-5381.1994.tb17122.x.

12) Chevalier G, Mori K, Oschman JL. The Effect of Earthing (Grounding) on Human Physiology. European Biology and Bioelectromagnetics. 2007; 1: 600- 21.

13) Chevalier G. Changes in pulse rate, respiratory rate, blood oxygenation, perfusion index, skin conductance, and their variability induced during and after grounding human subjects for 40 minutes. J Altern Complement Med. 2010; 16(1): 81-7. doi: 10.1089/acm.2009.0278. PMID: 20064020.

14) Sauer HH. Notes on the Natural Radiation Hazard at Aircraft Altitudes. CIRES/NOAA. 2000. Available from: http://legacy-www.swpc.noaa.gov/info/RadHaz.html.

15) Avicenna. Canon of Medicine (Book three Technique No. five) vol 2. Beirut -Lebanon: Alaalami Library publication; 2005: 434. 